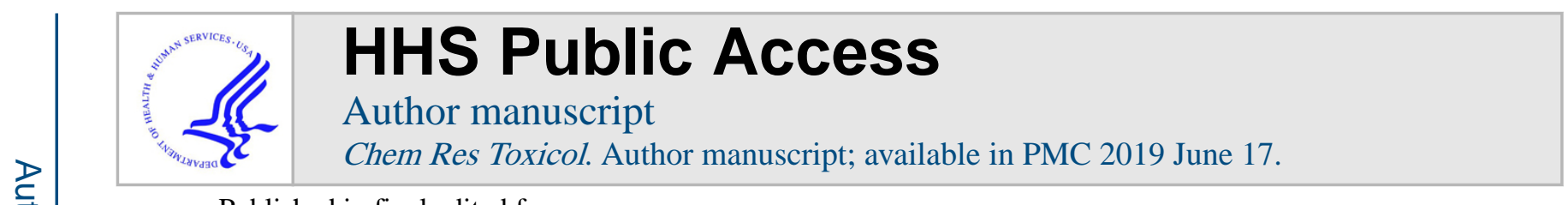

Published in final edited form as:

Chem Res Toxicol. 2015 October 19; 28(10): 1888-1890. doi:10.1021/acs.chemrestox.5b00301.

\title{
Scavenging 4-0xo-2-nonenal
}

\author{
Venkataraman Amarnath ${ }^{*}, \dagger$ and Kalyani Amarnath ${ }^{\ddagger}$ \\ tDepartment of Pathology, Microbiology and Immunology, Nashville, Tennessee 37232, United \\ States \\ ¥Division of Clinical Pharmacology Vanderbilt University Medical Center, Nashville, Tennessee \\ 37232, United States
}

\begin{abstract}
4-Oxo-2-nonenal (ONE), a product of cellular lipid oxidation, reacts nonspecifically with the lysine residues of proteins and is generated in increased amounts during degenerative diseases and cancer. We show that pyridoxamine, salicylamine, and related 2-aminomethylphenols react with ONE, to form pyrrolo[2,1- $b][1,3]$ oxazines with the participation of both the amino and the phenolic groups. 2-Aminomethylphenols react with ONE as well as with the Michael adducts of ONE much more rapidly than lysine, suggesting their use for therapeutically scavenging ONE.
\end{abstract}

\section{Graphical Abstract}<smiles>[X]c1ccc(CN)c(O)c1</smiles><smiles>CCCCCCCCc1ccc2n1Cc1ccccc1O2</smiles>
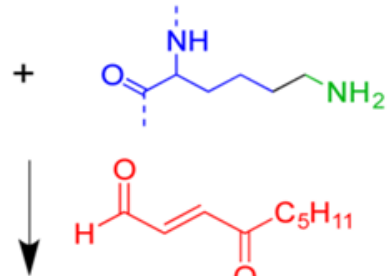<smiles>O=C/C=C/C(=O)c1ccccc1</smiles>

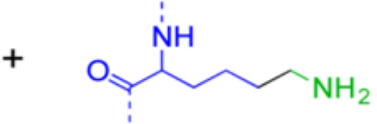

Reactive electrophiles produced by the peroxidation of fatty acids have been implicated in many diseases. ${ }^{1}$ Of the many such reactive aldehydes, the 2-alkenals 4-oxo-2-nonenal (ONE, 4) and 4-hydroxy-2-nonenal (HNE, 5) have attracted considerable attention. ONE is far

\footnotetext{
*Corresponding Author venkataraman.amarnath@vanderbilt.edu. ASSOCIATED CONTENT

The Supporting Information is available free of charge on the ACS Publications website at DOI: 10.1021/acs.chemrestox.5b00301. General methods; reactions of ONE and HNE in biological systems; detection of pyrrole in reactions with ONE by Ehrlich's reagent; chromatogram of the Michael adduct of $N$-acetylcysteine on ONE treated with PnPM; chromatogram of the reaction mixture containing PnPM with HNE; and progression of the reaction between ClSA and ONE (PDF)

DEDICATION

We dedicate this work to the memory of Professor S. V. Ananthakrishnan from whom we started learning chemistry, together and exactly 50 years ago.

The authors declare no competing financial interest.
} 
more reactive than $\mathrm{HNE},{ }^{2}$ and it reacts in different ways with various biomolecules (Scheme S1), ${ }^{3-6}$ thereby changing their structure and function. Modification of the lysyl residues of proteins to 4-ketononanamides appears to be the most damaging. ${ }^{7}$ The major reaction of HNE is Michael addition to the unsaturated aldehyde (Scheme S1). ${ }^{2,3}$

Another set of reactive aldehydes with a keto group at the 4-position are isoketals from free radical-mediated oxidation of arachidonic acid ${ }^{8}$ and levuglandins $\mathrm{LGE}_{2}$ and $\mathrm{LGD}_{2}$ formed by nonenzymic rearrangement of prostaglandin $\mathrm{H}_{2} \cdot{ }^{9}$ Pyridoxamine (1Pa, PM, Figure 1) and its benzene analogue salicylamine (1Ba, SA), with a 2-aminomethylphenol group, display extraordinary reactivity toward 1,4-dicarbonyls. The nucleophilic attack on one carbonyl group by the hemiaminal formed on the other is facilitated by the phenolic group at the 2position. ${ }^{10} \mathrm{SA}, \mathrm{PM}$, and their analogues form pyrroles with lipid-derived 4-ketoaldehydes 3 orders of magnitude faster than the $\varepsilon$-amino group of $N$-a-acetyllysine, thus scavenging them before they react with lysyl residues of proteins. ${ }^{11}$ We recently showed that alkylpyridoxamines, such as, $5^{\prime}-O$-pentylpyridoxamine (1Pb, PnPM) and $5^{\prime}-O$ hexylpyridoxamine (1Pc, HxPM) rapidly scavenge glyoxal and methylglyoxal that are elevated in diabetic patients. ${ }^{12}$ This enables them to protect arginine residues of proteins from 1,2-dicarbonyls.

Carnosine has been shown to bind to HNE and thereby reduce the adduction of HNE to proteins ${ }^{13,14}$ but finding a suitable scavenger for multifunctional ONE has proven difficult. Thiols (in $\mathrm{N}$-acetylcysteine and glutathione) very rapidly and imidazoles (in histidine and carnosine) less rapidly ${ }^{15}$ add to the carbon-carbon double bond of ONE, but the resulting Michael adducts containing the 4-oxoalkanal moiety are even more reactive toward lysine than ONE. ${ }^{16,17}$

Here, we report a novel reaction pathway by which 2-aminomethylphenols, which possess very low toxicity, ${ }^{18}$ react with ONE completely and rapidly, opening the door to scavenging ONE.

We detected pyrrole (Figure S1) in the reaction mixture (medium of 3:2 phosphate buffer, $\mathrm{pH}$ 7.4-acetonitrile was used in all the reactions, as suggested by Sayre ${ }^{19}$ and also to keep the reactants and products in solution) containing ONE and SA, PM, or 1-(aminomethyl)-2naphthalenol (1N), all characterized by the presence of the 2-aminomethylphenol moiety but not in the solution of ONE and 4-hydroxybenzylamine (4-HOBA) or 2-aminoethanol. We hypothesized that the phenolic group provided the extra nucleophile needed to enable ONE to form pyrrole. The consumption of ONE during the reaction was confirmed by LC. When ONE (1 mM) was incubated with SA (3 mM), only $9 \%$ of ONE remained after $30 \mathrm{~min}$.

The pyrrole was rather unstable, its concentration in the reaction increasing with time, but dropping off slowly. Hence, the rate of reaction of ONE with $\mathbf{1}$ was followed by the disappearance of the latter, and the second-order rate constants are given in Table 1. 2Aminomethylphenols react with ONE at about the same rate as they did with 4-oxopentanal, 10 but they will not be able to compete with thiols in reacting with ONE. However, they can complete the task of tying up ONE. ${ }^{16} \mathrm{ONE}$ was mixed with $\mathrm{N}$-acetylcysteine (AcCySH) (3 $\mathrm{mM}$ each), and the resulting adduct was treated with 1 equiv of PnPM or 5-ethylsalicylamine 
(1Bb, EtSA). The reaction was extremely rapid, ${ }^{16}$ complete within a minute, giving a pair of pyrroles ( 90:10, 3 in Scheme 1; Figure S2). Whether reacting with ONE or with the AcCySH adduct of ONE, adding one equivalent of $N$ - $a$-acetyllysine along with PnPM or EtSA did not alter the outcome of the reaction (Supporting Information) showing the inability of $\mathrm{N}$-a-acetyllysine to compete with $\mathbf{1}$ in reactivity.

It is tempting to visualize the addition of phenol across the carbon-carbon double bond of ONE as the required first step prior to pyrrole formation. However, for steric reasons, with the phenol ether of $\mathbf{1}$ attached at the 2- or 3-position, the resulting 4-oxononanal can only react with the amino group of another molecule. The inability of 4-HOBA to react with ONE to give pyrrole by following this pathway argues against it.

When 1 was mixed with HNE an equilibrium involving the starting amine and a pair of products ( 1:2, 25 to 40\%), most likely isomers of the Schiff base 6 (Scheme 1 and Figure $\mathrm{S} 3$ ), was established in about $2 \mathrm{~h}$. Analogous reaction with ONE to form $\mathbf{7}$ is reported to be much more rapid. ${ }^{20}$ In the reaction between PM derivatives and methylglyoxal, the initially formed imine was shown to undergo phenolic addition to form pyrido-1,3-oxazine. ${ }^{12}$ The imine 7 being a vinylog of the PM adduct of methylglyoxal is poised to undergo cyclization to 8 which is set for one more ring closure after the isomerization of the double bond to the cis-orientation (9). Dehydration to the multicyclic pyrrole (11) is irreversible and completes the reaction of 1 with ONE.

The electron-rich pyrrole $\mathbf{1 1}$ with two alkyl and one phenolic substituents is prone to oxidative degradation. Benzopyrrolooxazines $(\mathbf{1 1}, \mathrm{X}=\mathrm{CH})$ were found to be much more stable than the pyrido analogues $(\mathbf{1 1}, \mathrm{X}=\mathrm{N})$. We were able to prepare, purify, and characterize 1-pentyl-9H-benzo[e]pyrrolo[2,1-b]-[1,3]oxazine (11Ba) and 7-chloro-1pentyl-9H-benzo[e]-pyrrolo[2,1-b][1,3]oxazine (11Bc) (Supporting Information).

The course of the reaction between ONE and 5-chlorosalicylamine (1Bc, ClSA) was followed (Figure S4), and it appears that the initially formed cyclic adduct is slowly converted to the tricyclic 11Bc.

We have shown that 2-aminomethylphenols react with ONE in a unique way. They can scavenge ONE by reacting with the double bond as well as with the two carbonyl groups. When ONE does form a Michael adduct with thiols, the resulting 4-oxoaldehydes are rapidly consumed by the 2-aminomethylphenols before lysyl residues react with them.

Modification by ONE of histones that are rich in lysines has been shown to alter its function.

${ }^{7}$ We will be evaluating the efficacy of 2-aminomethylphenols in protecting proteins from ONE using histones in cultured cells. ${ }^{21}$

\section{Supplementary Material}

Refer to Web version on PubMed Central for supplementary material. 


\section{ACKNOWLEDGMENTS}

We thank Dr. Irene Zagol-Ikapitte for collecting NMR data.

Funding

This work was partially supported by National Cancer Institute grant CA187495.

\section{ABBREVIATIONS}

$\begin{array}{ll}\text { AcCySH } & N \text {-acetylcysteine } \\ \text { HNE } & \text { 4-hydroxy-2-nonenal } \\ \text { LC } & \text { liquid chromatography } \\ \text { PM } & \text { pyridoxamine } \\ \text { SA } & \text { salicylamine }\end{array}$

\section{REFERENCES}

(1). Uchida K (2000) Role of reactive aldehyde in cardiovascular diseases. Free Radical Biol. Med 28, 1685-1696. [PubMed: 10946210]

(2). Doorn JA, and Peterson DR (2002) Covalent modification of amino acid nucleophiles by the lipid peroxidation products 4-hydroxy-2-nonenal and 4-oxo-2-nonenal. Chem. Res. Toxicol 15, 14451450. [PubMed: 12437335]

(3). Lee SH, Takahashi R, Goto T, and Oe T (2010) Mass spectrometric characterization of modifications to angiotensin II by lipid peroxidation products, 4-oxo-2(E)-nonenal and 4hydroxy-2(E)-nonenal. Chem. Res. Toxicol 23, 1771-1785. [PubMed: 20977208]

(4). Shimozu Y, Shibata T, Ojika M, and Uchida K (2009) Identification of advanced reaction products originating from the initial 4-oxo-2-nonenal-cysteine Michael adducts. Chem. Res. Toxicol 22, 957-964. [PubMed: 19368367]

(5). Oe T, Lee SH, Silva Elipe MV, Arison BH, and Blair IA (2003) A novel lipid hydroperoxidederived modification to arginine. Chem. Res. Toxicol 16, 1598-1605. [PubMed: 14680374]

(6). Chou P-H, et al. (2010) Detection of lipid peroxidation-induced DNA adducts caused by 4oxo-2(E)-nonenal and 4-oxo-2(E)-hexenal in human autopsy tissues. Chem. Res. Toxicol 23, 1442-1448. [PubMed: 20849149]

(7). Galligan JJ, Rose KL, Beavers WN, Hill S, Tallman KA, Tansey WP, and Marnett LJ (2014) Stable histone adduction by 4-oxo-2-nonenal: A potential link between oxidative stress and epigenetics. J. Am. Chem. Soc 136, 11864-11866. [PubMed: 25099620]

(8). Davies SS, Amarnath V, and Roberts LJ (2004) Isoketals: highly reactive $\gamma$-ketoaldehydes formed from the $\mathrm{H}_{2}$-isoprostane pathway. Chem. Phys. Lipids 128, 85-99. [PubMed: 15037155]

(9). Boutaud O, Brame CJ, Salomon RG, Roberts LJ, and Oates JA (1999) Characterization of the lysyl adducts formed from prostaglandin $\mathrm{H} 2$ via the levuglandin pathway. Biochemistry 38, 9389-9396. [PubMed: 10413514]

(10). Amarnath V, Amarnath K, Amarnath K, Davies S, and Roberts LJ (2004) Pyridoxamine: An extremely potent scavenger of 1,4-dicarbonyls. Chem. Res. Toxicol 17, 410-415. [PubMed: 15025512]

(11). Davies SS, Brantley EJ, Voziyan PA, Amarnath V, Zagol-Ikapitte I, Boutaud O, Hudson BJ, Oates JA, and Roberts LJ (2006) Pyridoxamine analogs scavenge lipid-derived $\gamma$-ketoaldehydes against $\mathrm{H}_{2} \mathrm{O}_{2}$-mediated cytotoxicity. Biochemistry 45, 15756-13767. [PubMed: 17176098]

(12). Amarnath V, Amarnath K, Avance J, Stec DF, and Voziyan P (2015) 5' - O-Alkylpyridoxamines: lipophilic analogs of pyridoxamine are potent scavengers of 1,2-dicarbonyls. Chem. Res. Toxicol 28, 1469-1475. [PubMed: 26046387] 
(13). Liu Y, Xu G, and Sayre LM (2003) Carnosine inhibits (E)-4-hydroxy-2-nonenal-induced protein cross-linking: structural characterization of carnosine-HNE adducts. Chem. Res. Toxicol 16, 1589-1597. [PubMed: 14680373]

(14). Colzani M, Criscuolo A, De Maddis D, Garzon D, Yeum K-J, Vistoli G, Carini N, and Aldini G (2014) A novel high reolution MS approach for the screening of 4-hydroxy-trans-2-nonenal sequestering agents. J. Pharm. Biomed. Anal 91, 108-118. [PubMed: 24463041]

(15). Picklo MJ, Azenkeng A, and Hoffmann MR (2011) Trans-4-oxo-2-nonenal potently alters mitochondrial function. Free Radical Biol. Med 50, 400-407. [PubMed: 21092757]

(16). Zhu X, Gallogly MM, Mieyal JJ, Anderson VE, and Sayre LM (2009) Covalent cross-linking of glutathione and carnosine to proteins by 4-oxo-2-nonenal. Chem. Res. Toxicol 22, 1050-1059. [PubMed: 19480392]

(17). Aluise CD, Camarillo JM, Shimozu Y, Gallagan JJ, Rose KL, Tallman KA, and Marnett LJ (2015) Site-specific, intramolecular cross-linking of Pin 1 active site residues by the lipid electrophile 4-oxo-2-nonenal. Chem. Res. Toxicol 28, 817-827. [PubMed: 25739016]

(18). Zagol-Ikapitte I, Amarnath V, Bala M, Roberts LJ, Oates JA, and Boutaud O (2010) Characterization of scavengers of $\gamma$-ketoaldehydes that do not inhibit prostaglandin biosynthesis. Chem. Res. Toxicol 23, 240-250. [PubMed: 20041722]

(19). Sayre LM, Arora PK, Iyer RS, and Salomon RG (1993) Pyrrole formation from 4hydroxynonenal and primary amines. Chem. Res. Toxicol 6, 19-22. [PubMed: 8448343]

(20). Lin D, Lee H, Liu Q, Perry G, Smith MA, and Sayre LM (2005) 4-oxo-2-nonenal is both more neurotoxic and more protein reactive than 4-hydroxy-2-nonenal. Chem. Res. Toxicol 18, 12191231. [PubMed: 16097795]

(21). Carrier CJ, Zagol-Ikapitte I, Amarnath V, Boutaud O, and Oates JA (2014) Levuglandin forms adducts with Histone $\mathrm{H} 4$ in a cyclooxygenase-2-dependent manner, altering its interaction with DNA. Biochemistry 53, 2436-2441. [PubMed: 24684440] 
<smiles>[R4]c1ccc(O)c(CN)c1</smiles>

1Ba, $S A: R^{4}=H$

1Bb, EtSA: $\mathrm{R}^{4}=\mathrm{C}_{2} \mathrm{H}_{5}$

1Bc, CISA: $\mathrm{R}^{4}=\mathrm{Cl}$

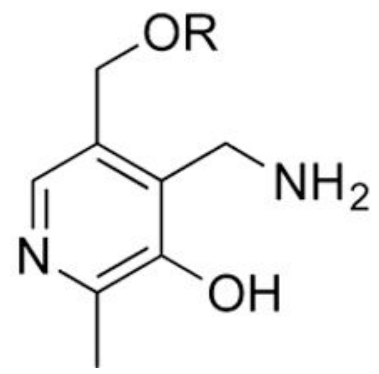

1Pa, PM: $\mathrm{R}=\mathrm{H}$

1Pb, PnPM: $\mathrm{R}=\mathrm{C}_{5} \mathrm{H}_{11}$

1Pc, HxPM: $\mathrm{R}=\mathrm{C}_{6} \mathrm{H}_{13}$<smiles>NCc1c(O)ccc2ccccc12</smiles>

$1 \mathrm{~N}$

Figure 1.

2-Aminomethylphenols. 

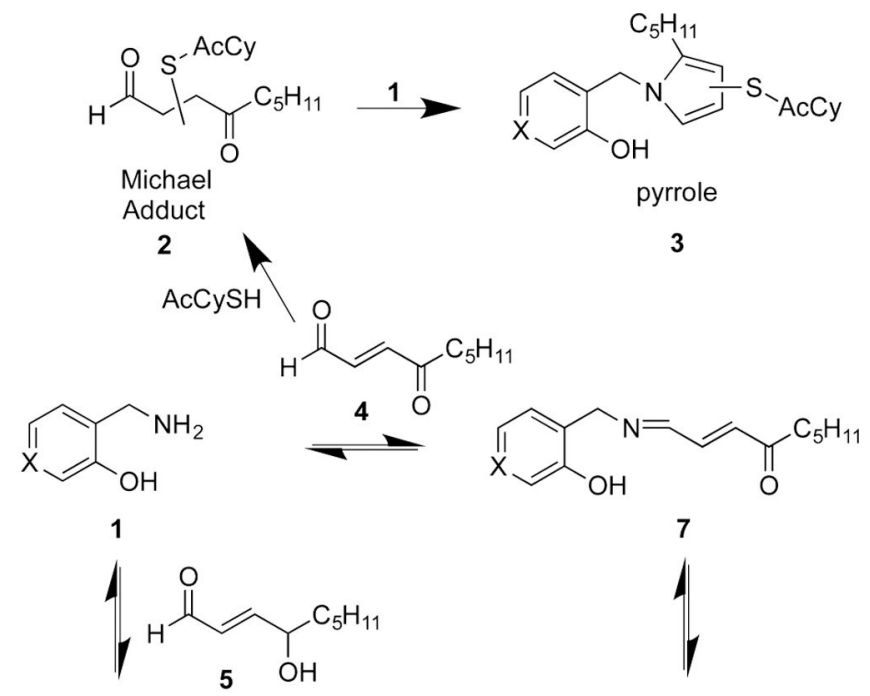<smiles>Oc1cccc(CN=C/C=C/C(O)c2ccccc2)c1O</smiles>

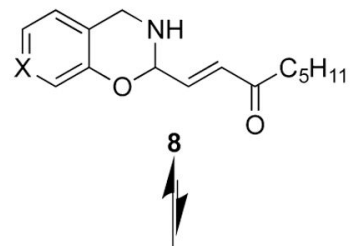<smiles>C[13CH2][C@H](C)O</smiles><smiles>[H][Y]1ccc2c(c1)OC1C=CC(=O)CN1C2</smiles>

10

9

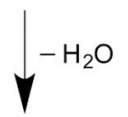

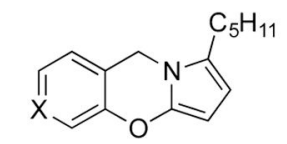

pyrrolo[2,1-b][1,3]oxazine

11

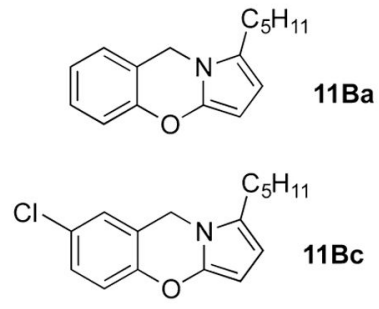

Scheme 1.

Reactions of 2-Aminomethylphenols with HNE and ONE 
Table 1.

Second-Order Rate Constants for the Reaction of 2-Aminomethylphenols with ONE

\begin{tabular}{lc}
\hline 2-aminomethylphenol & $\boldsymbol{a}$ \\
SA, 1Ba & $\boldsymbol{k} \times \mathbf{1 0}^{\mathbf{3}} \mathbf{s}^{\mathbf{- 1}} \mathbf{M}^{\mathbf{- 1}}$ \\
EtS, 1Bb & $70.2 \pm 2.9$ \\
ClSA, 1Bc & $87.0 \pm 1.6$ \\
PM, 1Pa & $215.6 \pm 7.3$ \\
PnPM, 1Pb & $86.5 \pm 2.8$ \\
HxPM, 1Pc & $347 \pm 19.9$ \\
$\mathbf{1 N}$ & $238 \pm 13.5$ \\
$N$-acetylcysteine ${ }^{15}$ & $150.6 \pm 3.3$ \\
\hline
\end{tabular}

${ }^{a}$ The rate constants for 1 and $\mathrm{ONE}$ ( $3 \mathrm{mM}$ each) were measured at $37^{\circ} \mathrm{C}$ in $3: 2$ phophate buffer (pH 7.4) and acetonitrile. 